\title{
Role of hypoxia-inducible factor-1 $\alpha$ in pathogenesis and disease evaluation of ulcerative colitis
}

\author{
CHUNMEI XU and WEIGUO DONG \\ Department of Gastroenterology, Renmin Hospital of Wuhan University, Wuhan, Hubei 430060, P.R. China
}

Received September 24, 2015; Accepted January 28, 2016

DOI: $10.3892 / \mathrm{etm} .2016 .3030$

\begin{abstract}
The main aim of the present study was to measure hypoxia-inducible factor- $1 \alpha(\mathrm{HIF}-1 \alpha)$ in serum and colonic mucosa of ulcerative colitis (UC) patients and to analyze its role in the pathogenesis, disease activity and severity of UC. A total of $47 \mathrm{UC}$ patients and $13 \mathrm{UC}$ in remission patients were recruited for the present study. Ten healthy subjects were also included to serve as controls. HIF-1 $\alpha$ in the serum was measured using ELISA. The citrate-microwave-SP immunohistochemical method was used to measure the expression of HIF- $1 \alpha$ in colonic mucosa. The results showed that, HIF-1 $\alpha$ in serum was notably higher in UC patients $(73.21 \pm 28.65)$ than UC in remission patients $(44.54 \pm 14.75)$ and controls $(42.83 \pm 15.49)$. The difference between UC patients and UC in remission patients was significant $(\mathrm{P}<0.05)$. A correlation analysis revealed that, the HIF-1 $\alpha$ level in serum was positively associated with disease activity, disease severity and endoscopic grade. The expression of HIF-1 $\alpha$ in colonic mucosa of UC patients was $(58.05 \pm 13.83)$ higher than that in UC in remission patients $(3.00 \pm 2.72)$ and controls $(3.04 \pm 2.69)$ and this difference was statistically significant $(\mathrm{P}<0.05)$. A positive correlation was identified between the expression of HIF-1 $\alpha$ in colonic mucosa and the disease activity, severity and endoscopic grade. Thus, the present findings indicated that, HIF-1 $\alpha$ is likely to play an important role in the pathogenesis of UC and may serve as a biomarker to evaluate disease activity and severity in UC patients.
\end{abstract}

\section{Introduction}

Ulcerative colitis (UC) is a chronic, non-specific colitis of unknown etiology $(1,2)$. Its etiology and pathogenesis are complex. UC is generally thought to be caused by the interaction between environmental factors, heredity, immune

Correspondence to: Dr Weiguo Dong, Department of Gastroenterology, Renmin Hospital of Wuhan University, 238 Jiefang Road, Wuhan, Hubei 430060, P.R. China

E-mail: 597627275@qq.com

Key words: ulcerative colitis, hypoxia inducible factor-1 $\alpha$, colonic mucosa, disease severity, erythropoietin, remission system, infection and mentality $(3,4)$. Assessment of the disease activity and severity of UC has clinical value in guiding clinical treatment and evaluating prognosis.

Hypoxia inducible factor-1 (HIF-1) (5-7) was identified by Semenza and Wang in 1992 (8) from the nuclear extract of the Hep3B cell line in which the protein was found to be bound to the enhancer of the erythropoietin (EPO) gene. HIF-1 in humans and other mammals under anoxic conditions forms a heterodimer with the HIF-1 $\alpha$ and HIF-1 $\beta$ subunit (9-11). The HIF-1 $\alpha$ subunit is regulated in an oxygen dependent-manner. HIF-1 $\alpha$ under low oxygen conditions escapes proteasome-mediated degradation and accumulates in the cell cytoplasm where it binds with HIF-1 $\beta$, and subsequently translocates to the nucleus to activate the transcription of target genes.

The present study aimed to measure HIF-1 $\alpha$ in serum and colonic mucosa of UC patients and UC in remission patients to examine its regulatory role in the pathogenesis of UC and to assess its relationship with disease activity and severity, thus providing a basis in the search of a clinically effective index to evaluate disease activity and severity.

\section{Materials and methods}

Patients. A total of 60 clinically confirmed UC patients who had visited the affiliated Xiangyang Hospital of Hubei Medical College (Wuhan, China) during the period January 2010 to September 2013 were included in this study. Of the 60 patients, 47 were active UC (28 males and 19 females) and 13 were UC in remission ( 9 males and 4 females). Ten healthy subjects (6 males and 4 females) were also included in this study and served as controls. The diagnostic criteria for UC were in accordance with China's IBD diagnosis consensus opinion in 2007 (12). Disease activity was measured following the improved Mayo scoring system and disease severity was graded according to the standards of Truelove and Witts while endoscopic grading was in line with the standards of Truelove.

Approval for the current study was obtained by the Institutional Ethics Committee of the affiliated Xiangyang Hospital of Hubei Medical College.

Analysis of HIF-1 $\alpha$ in serum. Blood (4 ml) was drawn in the morning and the serum portion was extracted. HIF-1 $\alpha$ was measured in the serum following the manufacturer's instructions (Sino-American Biotechnology Co., Ltd., Wuhan, China) 
Table I. HIF-1 $\alpha$ level in patients and controls.

\begin{tabular}{lcccc}
\hline Subjects & No. & Mayo scoring & Serum HIF-1 $\alpha(\mathrm{ng} / \mathrm{l})$ & HIF-1 $\alpha$-positive cells $(\%)$ \\
\hline Controls & 10 & - & $42.83 \pm 15.49$ & $3.04 \pm 2.69$ \\
UC in remission patients & 13 & $0.54 \pm 0.66$ & $44.54 \pm 14.75$ & $3.00 \pm 2.72$ \\
UC patients & 47 & $6.11 \pm 2.50$ & $73.21 \pm 28.65$ & $58.05 \pm 13.83$ \\
\hline
\end{tabular}

HIF-1 1 , hypoxia-inducible factor- $1 \alpha$; UC, ulcerative colitis.

using the ELISA method. Colonic mucosal tissue specimens were obtained from UC patients, UC in remission patients and from controls. The obtained specimens were fixed in $10 \%$ formalin and subsequently embedded in paraffin. The paraffin blocks were cut into $4 \mu \mathrm{m}$ sections which were stained with conventional hematoxylin and eosin (H\&E) and HIF-1 $\alpha$ specific antibody through immunohistochemistry. Briefly, the paraffin-embedded specimens were dewaxed and rehydrated by passing through a graded series of ethanol to distilled water. The sections were incubated with $3 \%$ hydrogen peroxide for 10 min to block the endogenous peroxidase activity. The sections were then boiled in sodium citrate buffer ( $\mathrm{pH}$ 6.0) to retrieve antigen. The sections were incubated with goat serum for $15 \mathrm{~min}$ at room temperature. HIF-1 $\alpha$ polyclonal rabbit antibody (1:100 dilution, Wuhan Boster Bio-Engineering Co., Ltd., Wuhan, China) was added and incubated overnight at $4^{\circ} \mathrm{C}$. The following day, the sections were rinsed in PBS three times and incubated with horseradish-peroxidase conjugated antibody for $15 \mathrm{~min}$. A DAB color developing substrate was added and the sections were examined microscopically for color development for 5-10 min, re-dyed with H\&E, mounted and visualized under the microscope (Olympus BX53, Tokyo, Japan). A polyclonal anti-goat HIF-1 $\alpha$ antibody (1:80) was used with PBS as a negative control.

Immunohistochemistry. The HIF-1 $\alpha$ protein which contained tan fine particles in the nucleus or cytoplasm was considered positive. Ten non-overlapping randomly selected fields were analyzed for each sample at a magnification of x400 and the images were captured. The captured images were analyzed using the HPIAS-2000 software (Techman, Chengdu, China) to scan HIF-1 $\alpha$-positive cells and to record the percentage and mean values for each sample.

Statistical analysis. The statistical software SPSS 14.0 version (SPSS, Inc., Chicago, IL, USA) was used to analyze the results. A normality test and the homogeneity test of variance were used to evaluate the statistical indicators. The analyzed data were presented as mean \pm standard deviation. The groups were compared by one-way analysis of variance and a correlation analysis was carried out using the Pearson linear and Spearman's rank correlation tests. $\mathrm{P}<0.05$ was considered to indicate a statistically significant difference.

\section{Results}

$H I F-1 \alpha$ is associated with pathogenesis of UC. The serum HIF-1 $\alpha$ level in UC patients was $(73.21 \pm 28.65)$, which was

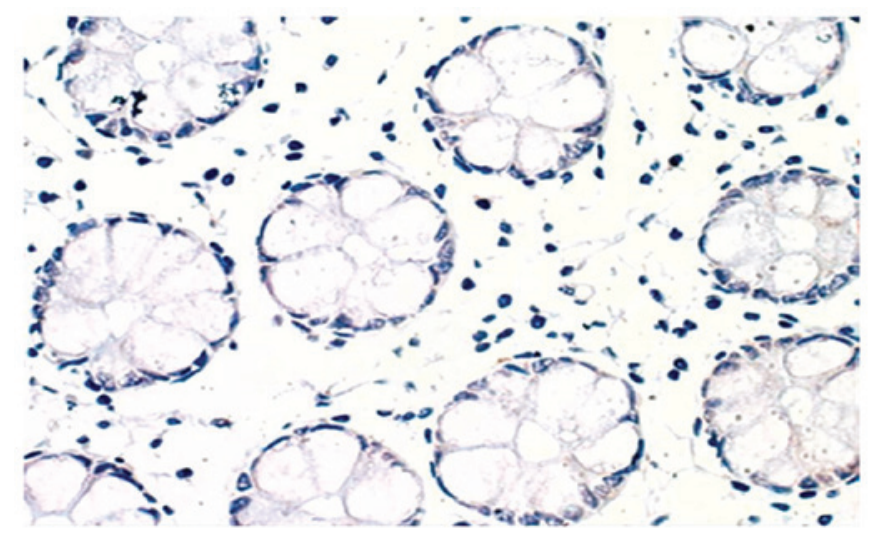

Figure 1. Normal colonic mucosa showing no hypoxia-inducible factor-1 $\alpha$ expression (magnification, $\mathrm{x} 400$ ).

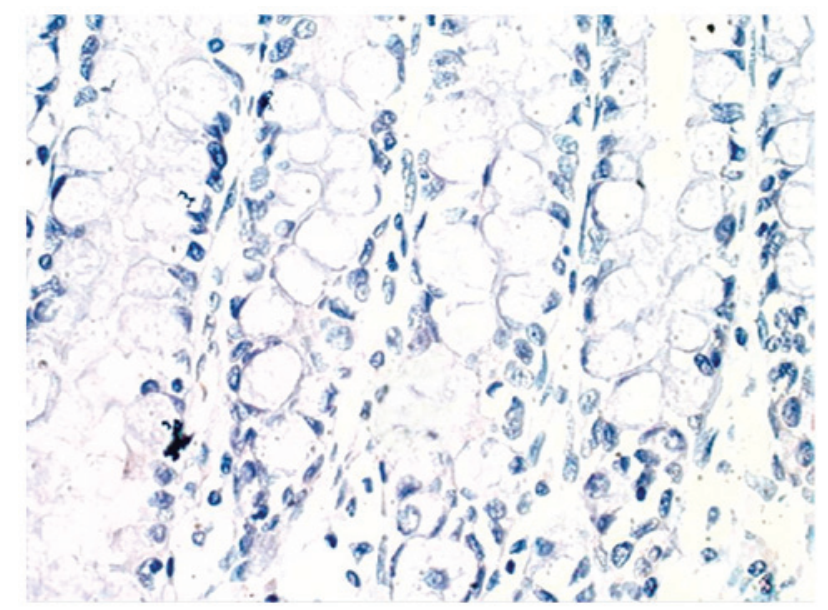

Figure 2. No hypoxia-inducible factor-1 $\alpha$ expression in the colonic mucosa of ulcerative colitis in remission patients (magnification, $\mathrm{x} 400$ ).

significantly $(\mathrm{P}<0.05)$ higher than that in $\mathrm{UC}$ in remission patients $(44.54 \pm 14.75)$ and controls $(42.83 \pm 15.49)$. However, the distribution of serum HIF-1 $\alpha$ was more or less similar between UC in remission patients and the controls $(\mathrm{P}>0.05$, Table I). The expression of HIF-1 $\alpha$ in colonic mucosa was found to be extremely high in UC patients $(58.05 \pm 13.83)$ in

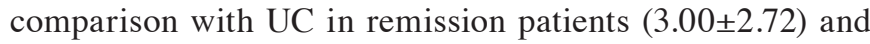
controls (3.04 \pm 2.69$)$. The difference between UC patients and $\mathrm{UC}$ in remission patients and controls was significant $(\mathrm{P}<0.05$, Table I). A low expression of HIF-1 $\alpha$ in colonic mucosa and no expression of HIF-1 $\alpha$ in healthy intestinal tissue of UC in 
Table II. Correlation of serum HIF- $1 \alpha$ level with disease severity and endoscopic grading in UC patients.

\begin{tabular}{lcccc}
\hline Parameters & $\begin{array}{c}\text { No. of } \\
\text { subjects }\end{array}$ & $\begin{array}{c}\text { Serum HIF-1 } \alpha \\
(\text { mean } \pm \text { SD) }\end{array}$ & $\begin{array}{c}\text { Correlation } \\
\text { index (r) }\end{array}$ & P-value \\
\hline $\begin{array}{l}\text { Disease } \\
\text { severity }\end{array}$ & & & 0.696 & 0.0002 \\
$\quad$ Low & 23 & $56.60 \pm 17.96$ & & \\
$\quad$ Moderate & 16 & $73.61 \pm 18.14$ & & \\
$\quad$ Severe & 08 & $120.16 \pm 15.81$ & & \\
Endoscopic & & & 0.674 & 0.00023 \\
grading & & & & \\
I & 18 & $55.65 \pm 19.94$ & & \\
II & 22 & $72.28 \pm 18.99$ & & \\
III & 7 & $121.29 \pm 16.73$ & & \\
\hline
\end{tabular}

HIF-1 $\alpha$, hypoxia-inducible factor-1 $\alpha$; UC, ulcerative colitis; $\mathrm{SD}$, standard deviation.

Table III. Correlation of HIF-1 $\alpha$ of colonic mucosa with disease severity and endoscopic grading in UC patients.

\begin{tabular}{lcccc}
\hline Parameters & $\begin{array}{c}\text { No. of } \\
\text { subjects }\end{array}$ & $\begin{array}{c}\text { HIF-1 } \alpha \text {-positive } \\
\text { cells }(\%)\end{array}$ & $\begin{array}{c}\text { Correlation } \\
\text { index (r) }\end{array}$ & P-value \\
\hline $\begin{array}{l}\text { Disease } \\
\text { severity }\end{array}$ & & & 0.699 & 0.00013 \\
$\quad$ Low & 23 & $49.02 \pm 10.69$ & & \\
$\quad$ Moderate & 16 & $58.75 \pm 10.23$ & & \\
$\quad$ Severe & 08 & $76.87 \pm 2.44$ & & \\
Endoscopic & & & 0.677 & 0.00026 \\
grading & & & & \\
I & 18 & $48.04 \pm 11.85$ & & \\
II & 22 & $58.11 \pm 9.98$ & & \\
III & 7 & $77.04 \pm 2.58$ & & \\
\hline
\end{tabular}

HIF-1 $\alpha$, hypoxia-inducible factor-1 $\alpha$; UC, ulcerative colitis; $\mathrm{SD}$, standard deviation.

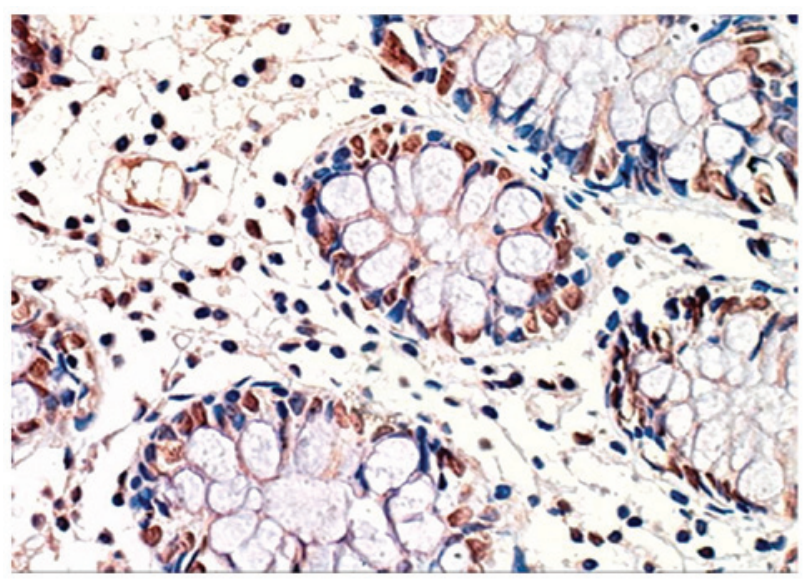

Figure 3. Hypoxia-inducible factor- $1 \alpha$ expression in the colonic mucosa of ulcerative colitis patients (low disease severity) (magnification, $\mathrm{x} 400$ ).

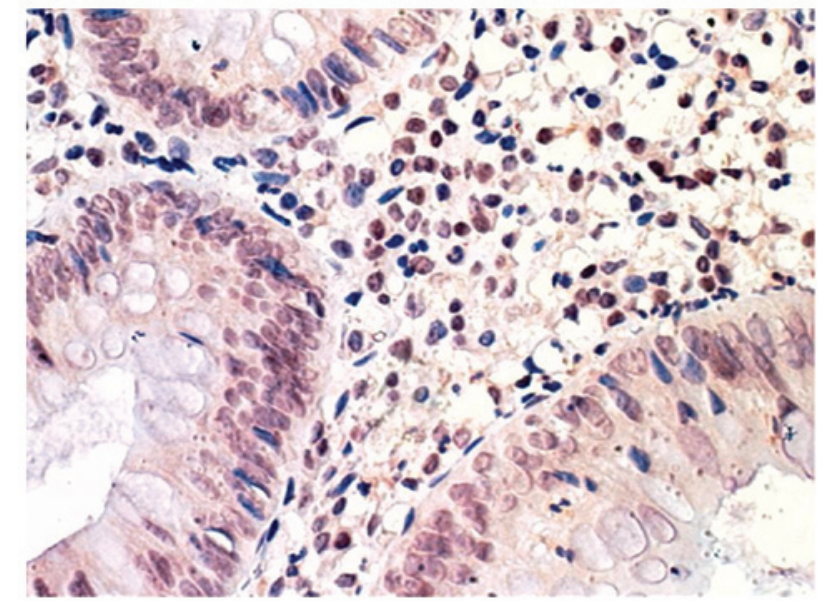

Figure 4. Hypoxia-inducible factor- $1 \alpha$ expression in the colonic mucosa of ulcerative colitis patients (moderate disease severity) (magnification, x400).

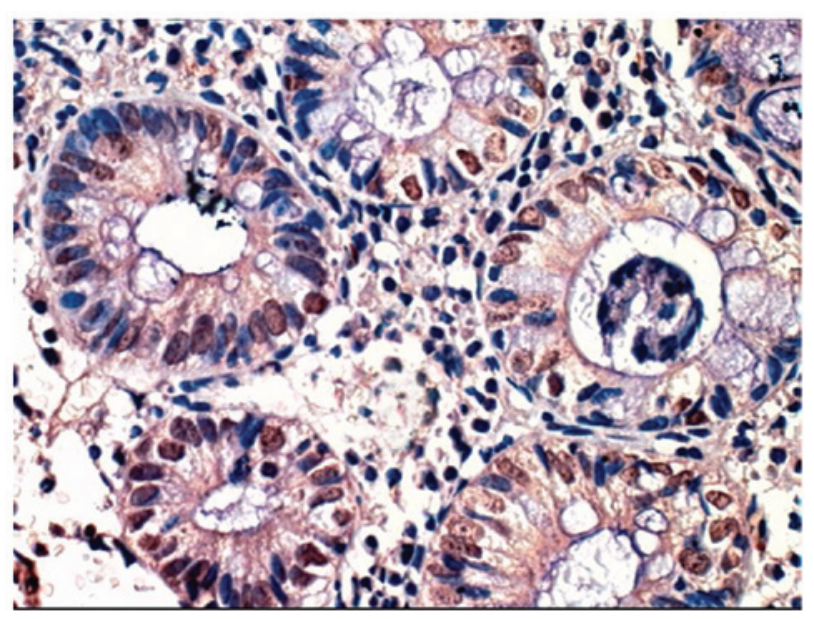

Figure 5. Hypoxia-inducible factor-1 $\alpha$ expression in the colonic mucosa of ulcerative colitis patients (severe disease severity) (magnification, $\mathrm{x} 400$ ).

remission patients were identified (Figs. 1 and 2). However, HIF-1 $\alpha$ was expressed was observed in epithelial cells of the enteric cavity and gland, endothelial cells of blood vessels, connective tissue cells on matrices and inflammatory cells of the intestinal tissue (Figs. 3-5). Thus, HIF-1 $\alpha$ expression increased with disease progression.

Correlation analysis. HIF- $1 \alpha$ level in serum and colonic mucosa of UC in remission patients was not correlated with Mayo scoring (serum HIF-1 $\alpha, \mathrm{r}=0.139, \mathrm{P}>0.05$; colonic mucosa HIF-1 $\alpha, r=0.108, P>0.05$ ). However, the expression level of HIF-1 $\alpha$ in serum and colonic mucosa was positively associated with Mayo scoring (serum HIF-1 $\alpha, \mathrm{r}=0.699, \mathrm{P}<0.01$; colonic mucosa HIF- $1 \alpha$; $\mathrm{r}=0.743, \mathrm{P}<0.01)$ in UC patients. Additionally, the expression level of HIF-1 $\alpha$ in serum demonstrated a positive correlation with disease severity $(r=0.696$, $\mathrm{P}<0.01)$ and endoscopic grading $(\mathrm{r}=0.674, \mathrm{P}<0.01$; Table II) in UC patients. Similarly, the expression level of HIF-1 $\alpha$ in the colonic mucosa of UC patients showed a significant correlation with disease severity $(\mathrm{r}=0.699, \mathrm{P}<0.01)$ and endoscopic grading $(\mathrm{r}=0.677, \mathrm{P}<0.01$, Table III). 


\section{Discussion}

Oxygen plays an essential role in metabolic activity and cell survival (13). Under anoxic conditions, several genes in cells are stimulated in order to respond to hypoxic stress such as CXCR4, KlHEM13 (14-16). Hypoxia causes metabolic disorders, functional disorders and various pathological and physiological changes that ultimately result in disease (17).

In UC, the apoptosis, proliferation of intestinal epithelial cells, endothelial cells, lymphocytes, accelerated metabolism and activation of the large number of blood platelets collectively affect the microcirculation in intestinal mucosa $(18,19)$. Those processes together constitute a local hypoxic microenvironment in the intestinal mucosa. Previous findings have shown different degrees of hypoxia in the intestinal mucosa of murine models and in patients with inflammatory bowel disease (20-22). During hypoxia the balance between oxygen supply and oxygen consumption in cells is damaged, which enables some hypoxia-inducible factors such as HIF-1 $\alpha$ to regulate different physiological and pathological reactions through different mechanisms (23). HIF-1 $\alpha$ is associated with diseases due to hypoxia, but is also involved in ischemia and many types of cancer. It also has a close association with the restoration and maintenance of intestinal barrier functions. HIF- $1 \alpha$ is able to regulate the expression of numerous target genes such as vascular endothelial growth factor, EPO, GAPDH, inducible nitric oxide synthase (iNOS), cyclooxygenase (COX)-2, insulin-like growth factor 2, ET-1, HIF-1 $\alpha$ transferrin and glycolytic enzymes. In chronic hypoxia, HIF-1 $\alpha$ and some of its target gene products, such as iNOS, COX-2, interleukin (IL)-6 and IL-8 (24), may also be involved in the various pathogenic processes in the manifestation of UC such as the regulation of inflammation, immunity and apoptosis. Findings of a previous study (25) showed that COX-2 and iNOS, which are regulated by HIF-1 $\alpha$, were not or were weakly expressed in normal intestinal mucosa, although their expression significantly increased in the intestinal mucosa of UC patients.

The current findings have confirmed that, in UC patients, serum HIF-1 $\alpha$ in colonic mucosa was expressed significantly higher than that of UC in remission patients and controls. Thus, hypoxia is present in UC and HIF-1 $\alpha$ and plays an important role in the pathogenesis of UC.

HIF-1 $\alpha$ expression is associated with inflammation. For example, lipopolysaccharide (LPS), the product of bacterial metabolism, strongly induces HIF-1 $\alpha$ expression in macrophage (26). Thus, it plays as an important role in LPS-induced inflammation. HIF-1 gene knockout inhibited the neutrophils and macrophages from eliciting an inflammatory response under hypoxic conditions, thereby preventing of inflammation (26). HIF-1 $\alpha$ has been studied in many inflammation-mediated diseases, including rheumatoid arthritis, chronic bronchitis, chronic obstructive pulmonary disease, acute pancreatitis, periodontitis and periodontal disease, chronic hepatitis, chronic nephritis, and verrucous gastritis (27-31) and it was identified that HIF-1 $\alpha$ participation in eliciting the inflammatory response was experimentally confirmed. HIF-1 $\alpha$ is a core transcription factor in oxygen homeostasis. Oxygen concentration is not the only factor that regulates HIF-1 $\alpha$, cytokines secreted during inflammatory condition have a significant regulatory role in HIF-1 $\alpha$ induction, DNA binding activity and expression of the backward genes (32). For instance, inflammation-associated cytokines such as IL-1 $\beta$, IL-6, tumor necrosis factor- $\alpha$ (TNF- $\alpha)$ and NO have a significant regulatory role in HIF-1 $\alpha$ protein accumulation, DNA binding activity and the expression of backward factors (32). By contrast, the role of inflammation-associated cytokines such as IL-1 $\beta$, IL- 6 , TNF- $\alpha$, and NO in the pathogenesis of UC have been confirmed (33-35). Under anoxic conditions, a positive feedback loop may be created as 'inflammation-inflammation medium-HIF-1 $\alpha$-inflammation medium-inflammation', in which HIF-1 $\alpha$ at least plays a role in the amplification of inflammation, making the existing inflammation response amplified and persistent.

In the present study, the HIF-1 $\alpha$ expression level in the serum and colonic mucosa of UC in remission patients was not correlated with Mayo scoring. However, in the UC patients, the HIF-1 $\alpha$ expression level in serum and colonic mucosa demonstrated an obvious correlation with Mayo scoring and had a significant positive correlation with disease severity and endoscopic grading (36). As the abovementioned hypotheses have been demonstrated in the current study, HIF-1 $\alpha$ may serve as a good index to assess disease activity and severity of UC.

In conclusion, the findings of the current study show that HIF-1 $\alpha$ is correlated with UC. However, its complicated molecular mechanism requires additional investigation, which might be of great significance in further explaining the pathogenesis of UC and in pursuing effective, innovative treatments targeting HIF-1 $\alpha$.

\section{References}

1. Diamanti A, Knafelz D, Panetta F, De Angelis P, Candusso M, Bracci F, Papadatou B, Francalanci P, Monti L and Torre G: Thalidomide as rescue therapy for acute severe ulcerative colitis. Eur Rev Med Pharmacol Sci 18: 1690-1693, 2014.

2. Hu D, Xia SL, Shao XX, Yu LQ, Lin XX, Guo M, Lin XQ and Jiang Y: Association of ulcerative colitis with TNF-related apoptosis inducing ligand (TRAIL) gene polymorphisms and plasma soluble TRAIL levels in Chinese Han population. Eur Rev Med Pharmacol Sci 19: 467-476, 2015.

3. Dong WG, Liu SP, Yu BP,Wu DF, Luo HS and Yu JP: Ameliorative effects of sodium ferulate on experimental colitis and their mechanisms in rats. World J Gastroenterol 9: 2533-2538, 2003.

4. Pica R, Cassieri C, Pronio AM, Zippi M, Avallone EV, Montesani C, Occhigrossi G and Paoluzi P: Quality of life in ulcerative colitis patients treated medically versus patients undergoing surgery. Eur Rev Med Pharmacol Sci 18: 693-698, 2014.

5. Bai R, Zhao AQ, Zhao ZQ, Liu WL and Jian DM: MicroRNA-195 induced apoptosis in hypoxic chondrocytes by targeting hypoxia-inducible factor 1 alpha. Eur Rev Med Pharmacol Sci 19: 545-551, 2015.

6. Wei H, Li F, Fu P and Liu X: Effects of the silencing of hypoxia-inducible factor-1 alpha on metastasis of pancreatic cancer. Eur Rev Med Pharmacol Sci 17: 436-446, 2013.

7. Zhang M, Gao X, Bai SJ, Ye XM and Zhang J: Effect of pioglitazone on expression of hypoxia-inducible factor $1 \alpha$ and vascular endothelial growth factor in ischemic hindlimb of diabetic rats. Eur Rev Med Pharmacol Sci 18: 1307-1314, 2014.

8. Semenza GL and Wang GL: A nuclear factor induced by hypoxia via de novo protein synthesis binds to the human erythropoietin gene enhancer at a site required for transcriptional activation. Mol Cell Bio 12: 5447-5454, 1992.

9. Maxwell PH, Pugh CW and Ratcliffe PJ: Activation of the HIF pathway in cancer. Curr Opin Genet Dev 11: 293-299, 2001.

10. Thornton RD, Lane $\mathrm{P}$, Borghaei Re, et al: Interleukin 1 induceshypoxia-inducible factor 1 in human gingival and synovialfibroblasts. Biochem J 350: 307-312, 2000. 
11. Albina JE, Mastrofrancesco B, Vessella JA, et al: HIF-1 expression in healing wounds:HIF-1alpha induction in primary inflammatory cells by TNF-alpha. Am J Physiol Cell Physiol 281: 1971-1977, 2001

12. Ouyang Q, Hu PJ, Qian JM, Zheng JJ and Hu RW: Consensus on the management of inflammatory bowel disease in China in 2007. J Dig Dis 8: 545-561, 2007

13. Urgesi R, Zampaletta C, Masini A, Pelecca G, Pastorelli A, De Lorenzo A and Faggiani R: Spontaneous right ventricular thrombus in a patient with active ulcerative colitis and protein $\mathrm{C}$ deficiency: a review with a case report. Eur Rev Med Pharmacol Sci 14: 455-463, 2010

14. Federico A, Tuccillo C, Grossi E, Abbiati R, Garbagna N, Romano M, Tiso A, Blanco CdelV and Loguercio C: The effect of a new symbiotic formulation on plasma levels and peripheral blood mononuclear cell expression of some pro-inflammatory cytokines in patients with ulcerative colitis: a pilot study. Eur Rev Med Pharmacol Sci 13: 285-293, 2009.

15. Blanco M1, Becerra M, González-Siso MI and Cerdán ME: Functional characterization of K1HEM13, a hypoxic gene of Kluyveromyces lactis. Can J Microbiol 51: 241-249, 2005.

16. Le QT and Denko NC and Giaccia AJ: Hypoxic gene expression and metastasis. Cancer Metastasis Rev 23: 293-310, 2004

17. Sanges M, Valente G, Rea M, Della Gatta R, De Franchis G, Sollazzo R and D'Arienzo A: Probiotics in spondyloarthropathy associated with ulcerative colitis: a pilot study. Eur Rev Med Pharmacol Sci 13: 233-234, 2009.

18. Schmidt C, Lautenschläger C, Petzold B, Sakr Y, Marx G and Stallmach A: Confocal laser endomicroscopy reliably detects sepsis-related and treatment-associated changes in intestinal mucosal microcirculation. Br J Anaesth 111: 996-1003, 2013.

19. Harrois A, Baudry N, Huet O, Kato H, Lohez M, Ziol M, Duranteau J and Vicaut E: Synergistic deleterious effect of hypoxemia and hypovolemia on microcirculation in intestinal villi. Crit Care Med 41: e376-e384, 2013.

20. Lehmann Ch, Abdo I, Kern H, Maddison L, Pavlovic D, Sharawi N, Starkopf J, Hall R, Johnson P, Williams L, et al MiDAS (Microcirculation Diagnostics and Applied Studies) group: Clinical evaluation of the intestinal microcirculation using sidestream dark field imaging - recommendations of a round table meeting. Clin Hemorheol Microcirc 57: 137-146, 2014.

21. Yeh YC, Sun WZ, Ko WJ, Chan WS, Fan SZ, Tsai JC and Lin TY: Dexmedetomidine prevents alterations of intestinal microcirculation that are induced by surgical stress and pain in a novel rat model. Anesth Analg 115: 46-53, 2012.

22. Armuzzi A, De Pascalis B, Lupascu A, Fedeli P, Leo D, Mentella MC, Vincenti F, Melina D, Gasbarrini G, Pola P, et al: Infliximab in the treatment of steroid-dependent ulcerative colitis. Eur Rev Med Pharmacol Sci 8: 231-233, 2004

23. Giatromanolaki A, Sivridis E, Maltezos E, Papazoglou D, Simopoulos C, Gatter KC, Harris AL and Koukourakis MI: Hypoxia inducible factor 1alpha and 2alpha overexpression in inflammatory bowel disease. J Clin Pathol 56: 209-213, 2003.
24. Jeong HJ, Chung HS, Lee BR, Kim SJ, Yoo SJ, Hong SH and Kim HM: Expression of proinflammatory cytokines via HIF-1alpha and NF-kappaB activation on desferrioxamine-stimulated HMC-1 cells. Biochem Biophys Res Commun 306: 805-811, 2003

25. Xu CM, Dong WG, Yu BP, et al: Expression of hypoxia-inducible factor- $1 \alpha$ and inflammation-induced enzyme in inflammatory bowel disease. J Clinical Gastroente 17: 103-105, 2005.

26. Cramer T, Yamanishi Y, Clausen BE, Förster I, Pawlinski R, Mackman N, Haase VH, Jaenisch R, Corr M, Nizet V, et al: HIF-1alpha is essential for myeloid cell-mediated inflammation. Cell 112: 645-657, 2003

27. Hu F, Liu H, Xu L, et al: Hypoxia-inducible factor-1 $\alpha$ perpetuates synovial fibroblast interactions with $\mathrm{T}$ cells and $\mathrm{B}$ cells in rheumatoid arthritis. Eur J Immunol: November 25, 2015 (Epub ahead of print). doi: 10.1002/eji.201545784.

28. Zhang X,Liu J, Wan L, et al: Up-regulated expressions of HIF-1 $\alpha$, VEGF and CD34 promote synovial angiogenesis in rats with adjuvant arthritis. Xi Bao Yu Fen Zi Mian Yi Xue Za Zhi 31: 1053-1056, 2015

29. Lee SH, Lee SH, Kim CH, et al: Increased expression of vascular endothelial growth factor and hypoxia inducible factor- $1 \alpha$ in lung tissue of patients with chronic bronchitis. Clin Biochem 47: 552-559, 2014

30. Tao H, Luo W, Pei H, Zhu S, Zhang M, Chen B, He J, Zhang M and Zhou R: Expression and significance of hypoxia-inducible factor-1 $\alpha$ in patients withchronic obstructive pulmonary disease and smokers with normal lung function. Xi Bao Yu Fen Zi Mian Yi Xue Za Zhi 30: 852-855, 2014.

31. Liu JB, Ding JQ and Wang L: Immunohistochemical study of dental pulp inflammation of hypoxia-inducible factor- $1 \alpha$. J Clin Stomatol 19: 77-78, 2003

32. Hellwig-Bürgel T, Rutkowski K, Metzen E, Fandrey J and Jelkmann W: Interleukin-1beta and tumor necrosis factor-alpha stimulate DNA binding of hypoxia-inducible factor-1. Blood 94: 1561-1567, 1999

33. Wang BL and Wang XR: Regulation of hypoxia inducible factor- $1 \alpha$ by the inflammatory mediators. Int $\mathrm{J}$ Pathol Clin Med 90: 1673-2588, 2008

34. Ngo DT, Farb MG, Kikuchi R, Karki S, Tiwari S, Bigornia SJ, Bates DO, LaValley MP, Hamburg NM, Vita JA, et al: Antiangiogenic actions of vascular endothelial growth factor-A165b, an inhibitory isoform of vascular endothelial growth factor-A, in human obesity. Circulation 130: 1072-1080, 2014.

35. Cătană CS, Berindan Neagoe I, Cozma V, Magdaș C, Tăbăran F and Dumitraşcu DL: Contribution of the IL-17/IL-23 axis to the pathogenesis of inflammatory bowel disease. World J Gastroenterol 21: 5823-5830, 2015.

36. Avallone EV, Pica R, Cassieri C, Zippi M, Paoluzi P and Vernia P: Azathioprine treatment in inflammatory bowel disease patients: type and time of onset of side effects. Eur Rev Med Pharmacol Sci 18: 165-170, 2014. 